\title{
Screening for Somatoform Disorders in Children and Adolescents
}

\author{
S. Winter ${ }^{1}$, C. Quinnn' ${ }^{1}$ K. Lenz ${ }^{2}$, E. Pfeiffer ${ }^{1}$, U. Lehmkuhl1 \\ ${ }^{1}$ Department of Child and Adolescent Psychiatry, Psychosomatics and Psychotherapy, \\ Charité-Universitätsmedizin, Berlin, Germany \\ ${ }^{2}$ Institute of Medical Biometrics and Clinical Epidemiology, Charité-Universitätsmedizin, Berlin, Germany \\ Email: Sibylle.Winter@charite.de
}

Received 9 July 2014; revised 5 August 2014; accepted 1 September 2014

Copyright (C) 2014 by authors and Scientific Research Publishing Inc.

This work is licensed under the Creative Commons Attribution International License (CC BY). http://creativecommons.org/licenses/by/4.0/

\section{Open Access}

\begin{abstract}
Until now, no German diagnostic instrument existed for somatoform disorders in children and adolescents. Therefore the Screening for Somatoform Disorders in Children and Adolescents (SOMS-CA) was developed based on the SOMS-2 (Screening for Somatoform Disorders 2) (Rief \& Hiller, 2008). This study investigates to what extent the SOMS-CA can differentiate significantly between children and adolescents with clinically diagnosed somatoform disorders and a control group and whether the SOMS-CA is superior to the GSCL-C (Giessen Subjective Complaint List for Children) (Braehler, 1992). 30 patients (11 - 17 years) with somatoform disorders and a control group $(n=31)$ were examined with the SOMS-CA $(N=61)$. The results from the SOMS-CA in both groups were compared with one another by means of a contingency analysis (chi-square test). The sensitivity and specificity were calculated and an optimal cut-off value was determined (Receiver Operating Characteristic curve (ROC-curve) analysis). A comparison analysis of the ROC-curves of the SOMS-CA and the GSCL-C followed. The sum score of complaints in the patients was significantly higher than that in the control group. The ROC-curve for the SOMS-CA demonstrates its excellent ability to differentiate between the two groups with an AUC (area under the curve) $=0.983$ ( $S E=0.14 ; \mathrm{N}=61$ ). The sensitivity was $97.6 \%$, the specificity $96.8 \%$. In comparison to the AUC of the GSCL-C the SOMS-CA shows a much higher result. The SOMS-CA successfully identifies patients with somatoform disorders from a paediatric population and differentiates from healthy test subjects. A comparison to the GSCL-C shows a considerable superiority of the SOMS-CA. Further studies on the validity of the SOMS-CA are necessary.
\end{abstract}

\section{Keywords}

Somatoform Disorders in Children and Adolescents, Diagnostics, SOMS-CA, Sensitivity, Specificity 


\section{Introduction}

The prevalence of somatoform disorders in children and adolescents (ICD-10: F45, DSM IV: 300, 307) is 11\% in girls and 4\% in boys (Fritz, Fritsch, \& Hagino, 1997). Even more common are functional disorders with a prevalence of up to 25\% (Huertas-Ceballos, Logan, Bennett, \& Macarthur, 2009). In a study of primary care patients, 39.6\% of patients with somatoform disorders revealed a psychiatric comorbidity (PSC-29) closely associated with internalising behaviour symptoms (Campo, Jansen-McWilliams, Comer, \& Kelleher, 1999). Somatoform disorders tend towards a protracted, chronic progression of disease. Furthermore, studies reveal that these patients are more likely to suffer from anxiety or depression (Hotopf, Carr, Mayou, Wadsworth, \& Wessely, 1998) or physical illness (Di Lorenzo et al., 2005) later in life. Retrospective studies in adult patients showed that initial symptoms in $75 \%$ of adult patients occur before the age of 20 years (Tomasson, Kent, \& Coryell, 1991). Bass and Murphy (1995) identify the average age at which adult patients claim to have first suffered initial symptoms as being 14 years.

Somatoform disorders lead to significant impairment in the quality of life of patients and their families with high levels of subsequent stress and strains. The high level of subjective impairment leads to a high healthcare utilisation, sometimes including invasive medical diagnostics (Lindley, Glaser, \& Milla, 2005). In paediatric patients with somatoform disorders, there is often a dramatic discrepancy between psychological/psychiatric and physical assessments (Winter et al., 2012; Winter et al., 2013). Only 3\% of the afflicted receive appropriate child and adolescent psychiatric diagnostics and treatment (Perquin et al., 2001). This can lead to school absentism, social retreat and degradation within the family environment (Noeker, 2008).

These findings highlight the necessity for an improved interdisciplinary approach, as well as the implementation of psychosomatic basis diagnostics within the somatic primary health care system in order to facilitate further interdisciplinary treatment. In the English speaking world the Children's Somatization Inventory (CSI) (Walker \& Garber, 1992; Walker, Garber, \& Greene, 1991) is established as a screening instrument for the assessment of somatoform symptoms in children and adolescents. In German speaking countries no reliable diagnostic assessment of somatoform disorders in children and adolescents can be found. While the Child Behavior Checklist (CBCL)/Youth Self-Report (YSR) (Achenbach, 1991a, 1991b) and the Giessen Subjective Complaint List for Children (GSCL-C) (Braehler, 1992) offer lists of somatoform symptoms, none are intended for the assessment of diagnostic criteria for somatoform disorders. Furthermore, no modules for somatoform disorders exist in common diagnostic interviews for children and adolescents, such as the K-SADS-PL (Kaufman, Birmaher, Brent, Rao, \& Ryan, 1996) and the DISYPS-KJ (Döpfner \& Lehmkuhl, 2003). There is a computer based diagnostic interview for adolescents aged 16 years and above, namely the Composite International Diagnostic Interview and its revisions (CIDI/DIA-X) (Wittchen \& Pfister, 1997) which permits the diagnosis of psychological disorders according to ICD-10 and DSM-IV including somatoform disorders.

For adults, German questionnaires for the assessment of somatoform disorders exist, such as the Screening for Somatoform Disorders (SOMS-2) (Rief \& Hiller, 2008). In the psychiatric sector the Quantification Inventory for Somatoform Syndromes (QUISS) (Wedekind, Bandelow, Fentzahn, Trumper, \& Ruther, 2007) is available, which was developed for the measurement of symptom progression and the evaluation of therapeutic outcome. As well as somatoform symptoms, both questionnaires have items relating to functional impairment and to illnessspecific behaviour and attitudes.

The following study highlights the current lack of an evaluated German screening for the identification of somatoform disorders in children and adolescents. In order to address this, a Screening for Somatoform Disorders in Children and Adolescents (SOMS-CA) was developed based on the Screening for Somatoform Disorders (SOMS-2). By means of a pilot study it was evaluated to what extent the SOMS-CA can differentiate between children and adolescents of a healthy control group and a patient group with clinically diagnosed somatoform disorders. This extent of differentiation was compared with the existing GSCL-C questionnaire.

\section{Methods}

A total of 30 patients and 31 healthy control subjects were included in the study. All data was calculated in analysis software SPSS. The patient group and the control group did not vary significantly from one another in terms of gender, age, migration background, intellectual ability, and socioeconomic status. The distribution of diagnoses in the patient group can be seen in Table 1.

The inclusion criteria were: the principal diagnosis of a somatoform disorder, age between 11 - 17 years, 
Table 1. Diagnoses of the patients $(n=30)$.

\begin{tabular}{|c|c|c|}
\hline ICD-10 diagnosis & $\mathrm{n}$ & $\%$ \\
\hline Somatoform/dissocative disorder & 30 & 100 \\
\hline F45.0 Somatisation disorder & 3 & 10.0 \\
\hline F45.1 Undifferentiated somatisation disorder & 8 & 26.7 \\
\hline F45.3 Somatoform autonomous functional disorder & 4 & 13.3 \\
\hline F45.4 Somatoform pain disorder & 13 & 43.3 \\
\hline F44 Dissociative disorder & 2 & 6.7 \\
\hline Psychiatric comorbidity & 14 & 46.7 \\
\hline Depressive disorders (F32, F33, F34.1) & 8 & 26.7 \\
\hline Emotional disorders with onset to childhood (F93) & 3 & 10 \\
\hline Hyperkinetic disorders (F90) & 3 & 10 \\
\hline
\end{tabular}

IQ $\geq 70$ and sufficient competency in the German language. Patients with dissociative disorders were included because they are classified under somatoform disorders in the DSM (DSM-IV in 2010). Patients with a somatoform disorder who suffered primarily from anxiety or depression were excluded from the study in order to minimise confounders. All patients were thoroughly examined and clinically diagnosed as a prerequisite by experienced children's psychiatrists of our clinic. All patients showed severe cases of somatoform disorders and required in-patient hospital treatment. The recruitment of the control group (11 - 17 years) took place during the same period. Their exclusion criteria were: psychiatric disorders, IQ $<70$ and insufficient competency in German. All participants and their parents were required to sign consent forms declaring voluntary participation.

The diagnostic instruments used are described as follows. In order to exclude or assess psychiatric disorders in children and adolescents according to the criteria as set out in ICD-10, a semi-structured psychiatric interview was conducted (Kiddie-Sads-Present and Lifetime Version, K-Sads-PL) (Kaufman et al., 1996). Part 1 (in extended form) of the CFT 20-R basic intelligence test scale 2-Revision (Weiß, 2006) was used for the evaluation of the intellectual capability. Furthermore, an existing German complaint scale such as the Giessen Subjective Complaint List for Children (GSCL-C) (Braehler, 1992) was applied alongside for comparison and validation purposes.

The Screening for Somatoform Disorders in Children and Adolescents (SOMS-CA) was developed on the basis of the SOMS-2 (Rief \& Hiller, 2008) and the QUISS (Wedekind et al., 2007). The SOMS-CA is a selfassessment questionnaire for an age range of 11 to 17 years and comprises a list of 31 symptoms, 17 questions on quality of life and illness-relevant behaviour and 3 questions on differential diagnoses (Table 2 and Table 3).

The symptom list of the SOMS-2 for adults (53 items from ICD-10 and DSM-IV) was reviewed with full consideration of its relevance for children and adolescents. A qualitative analysis of clinical records was carried out for 66 patients (48 girls, 18 boys) aged between 7 and 18 years (median $=13.8$ ) with somatoform (ICD 10: F45.0 - F45.9) or dissociative disorders (ICD 10: F44.4 - F44.8) (Brockhaus, 2008). As well as the file analysis, symptoms, which were deemed to be significant in other studies on somatoform symptoms in children/adolescents, were accounted for in the questionnaire. These include symptoms such as weakness, tiredness and a lump in one's throat (Eminson, Benjamin, Shortall, Woods, \& Faragher, 1996; Essau, Conradt, \& Petermann, 2000; Walker et al., 1991). During the development of the SOMS-CA, alongside the revision of the list of symptoms, questions relating to quality of life and illness-relevant behaviour played an important role because of their (differential) diagnostic importance (Eminson et al., 1996; Essau et al., 2000; Fritz et al., 1997; Rief \& Hiller, 1999; Walker, Garber, Smith, Van Slyke, \& Claar, 2001). From a total of ten questions relating to quality of life and illness-specific behaviour in the SOMS-2, seven were adopted and their content and formality modified to suit the age group. Consideration of the QUISS led to the selection of a further six questions. The evaluation of the SOMS-CA follows that of the SOMS-2. A total of seven points can be scored in the SOMS-CA. By derogation from SOMS-2, a point is awarded in SOMS-CA if at least one complaint from the symptom list is answered in the affirmative (Table 2). With regard to more monosymptomatic courses of somatoform disorders in young patients (Fritz et al., 1997; Pfeiffer, Schröder, \& Lehmkuhl, 1997) as opposed to polysymptomatic courses in adults, we consider one tagged symptom to suffice for a point in the screening. For the questions relating to quality of life and illness-specific behaviour, six issues (questions 4, 11, 12, 13, 18 and at least one tagged out of 
Table 2. List of symptoms: Comparison of patients and control group.

\begin{tabular}{|c|c|c|c|c|c|}
\hline Categories & Symptoms & Patients $(\mathrm{N}=30)$ & Control group $(\mathrm{N}=31)$ & $\mathrm{Chi}^{2}$ & $p$ \\
\hline \multirow[t]{9}{*}{ Pain symptoms } & Headache & $90 \%$ & $41.9 \%$ & 15.602 & $.000^{* * *}$ \\
\hline & Stomache pain & $56.7 \%$ & $35.5 \%$ & 2.755 & .126 \\
\hline & Back pain & $36.7 \%$ & $29.0 \%$ & .403 & .592 \\
\hline & Joint pain & $27.6 \%$ & $12.9 \%$ & 2.019 & .204 \\
\hline & Pain in arms/legs/hands/feet & $20.7 \%$ & $6.5 \%$ & 2.629 a & .104 \\
\hline & Chest pain & $13.8 \%$ & $3.2 \%$ & $2.190 \mathrm{a}$ & .188 \\
\hline & Earache & $23.3 \%$ & $6.7 \%$ & $3.268 \mathrm{a}$ & .145 \\
\hline & Pain during urination & $13.8 \%$ & $.0 \%$ & $4.581 \mathrm{a}$ & $.049^{*}$ \\
\hline & Pain in or around the genital area & $6.9 \%$ & $.0 \%$ & $2.212 \mathrm{a}$ & .229 \\
\hline \multirow[t]{5}{*}{$\begin{array}{l}\text { Gastrointestinal } \\
\text { symptoms }\end{array}$} & Nausea & $56.7 \%$ & $30.0 \%$ & 4.344 & .067 \\
\hline & Vomiting & $33.3 \%$ & $.0 \%$ & 12.359 a & $.000^{* * *}$ \\
\hline & Loss of appetite & $36.7 \%$ & $22.6 \%$ & 1.454 & .270 \\
\hline & Diarrhoea & $30.0 \%$ & $3.3 \%$ & 7.680 & $.012^{*}$ \\
\hline & Constipation & $17.2 \%$ & $.0 \%$ & 5.651 a & $.024^{*}$ \\
\hline \multirow[t]{5}{*}{$\begin{array}{l}\text { Cardiorespiratory } \\
\text { symptoms }\end{array}$} & Lump in one's throat & $10.0 \%$ & $12.9 \%$ & $.126 \mathrm{a}$ & 1.0 \\
\hline & Coughing & $30.0 \%$ & $30.0 \%$ & .000 & 1.0 \\
\hline & $\begin{array}{l}\text { Shortness of breath or sensation } \\
\text { of suffocation }\end{array}$ & $33.3 \%$ & $6.5 \%$ & 6.972 & $.011^{*}$ \\
\hline & $\begin{array}{c}\text { Heart palpitations/ } \\
\text { Heart flutter }\end{array}$ & $27.6 \%$ & $6.5 \%$ & 4.819 a & $.039^{*}$ \\
\hline & Tiredness & $60.0 \%$ & $35.5 \%$ & 3.674 & .074 \\
\hline \multirow[t]{12}{*}{$\begin{array}{l}\text { Pseudoneurological } \\
\text { symptoms }\end{array}$} & Paralysis. muscle weakness & $26.7 \%$ & $3.2 \%$ & 6.661 a & $.012^{*}$ \\
\hline & Numbness. pins and needles & $20.0 \%$ & $12.9 \%$ & $.560 \mathrm{a}$ & .508 \\
\hline & Muscle twitching & $23.3 \%$ & $12.9 \%$ & 1.122 & .335 \\
\hline & Heaviness in arms/legs & $20.0 \%$ & $6.5 \%$ & 2.456 a & .147 \\
\hline & $\begin{array}{c}\text { Gait disturbances/ } \\
\text { Difficulties in walking or standing }\end{array}$ & $16.7 \%$ & $3.2 \%$ & 3.106 a & .104 \\
\hline & $\begin{array}{c}\text { Visual impairment. } \\
\text { double vision }\end{array}$ & $16.7 \%$ & $.0 \%$ & 5.628 a & $.024^{*}$ \\
\hline & $\begin{array}{l}\text { Speech disorders. loss of } \\
\text { voice. hoarseness }\end{array}$ & $20.0 \%$ & $19.4 \%$ & .004 & 1.0 \\
\hline & Seizures & $26.7 \%$ & $6.5 \%$ & 4.546 a & $.043^{*}$ \\
\hline & Trembling & $23.3 \%$ & $3.2 \%$ & $5.410 \mathrm{a}$ & $.026^{*}$ \\
\hline & Dizziness & $53.3 \%$ & $16.1 \%$ & 9.348 & $.003^{* *}$ \\
\hline & Loss of consciousness/fainting & $20.0 \%$ & $3.2 \%$ & $4.223 \mathrm{a}$ & .053 \\
\hline & $\begin{array}{l}\text { Hearing difficulties } \\
\text { Buzzing/ringing in the ears }\end{array}$ & $13.3 \%$ & $10.0 \%$ & $.162 \mathrm{a}$ & 1.0 \\
\hline
\end{tabular}

Chi2-test: ${ }^{*} p<.05,{ }^{* *} p<.01,{ }^{* * *} p<.001$, a: minimal expected frequency of $<5$ : Fisher-test.

questions 5 - 8) are taken into account, which can also be found in diagnostic criteria (Table 3).

The following statistical analyses were made use of in the study: By using the Receiver Operating Characteristic (ROC) analysis it was possible to generate an optimal cut-off value as well as values for sensitivity (correctly positive) and specificity (correctly negative) for the SOMS-CA. The result provides an evaluation of the test's ability to differentiate. A ROC analysis was carried out, in which the dependent variable was defined as the total score of the SOMS-CA and the state variable was defined as the actual state of disease, which was measured by means of a clinical interview adopting the current gold standard which follows the two categories 
Table 3. Questions on quality of life and on illness-specific behaviour.

\begin{tabular}{|c|c|c|c|}
\hline Questions & Patients $(\mathrm{N}=30)$ & Control group $(\mathrm{N}=31)$ & $p$ \\
\hline 1. Feeling healthy & $27.6 \%$ & $87.1 \%$ & $.000^{* * * *}$ \\
\hline 2. Health concern & $63.3 \%$ & $12.9 \%$ & $.000^{* * *}$ \\
\hline \multicolumn{4}{|l|}{ (3. Symptom list. see Tab. 2) } \\
\hline 4. Impairment to general wellbeing & $83.3 \%$ & $11.1 \%$ & $.000^{* * *}$ \\
\hline 5. Disturbance of daily routine & $66.6 \%$ & $10.7 \%$ & $.000^{* * *}$ \\
\hline 6. Impairment to everyday school life & $73.3 \%$ & $14.3 \%$ & $.000^{* * *}$ \\
\hline 7. Impairment to free time & $69.0 \%$ & $7.1 \%$ & $.000^{* * *}$ \\
\hline 8. Disruption to family life & $23.3 \%$ & $3.6 \%$ & .053 \\
\hline 9. Changes to family interaction & $34.5 \%$ & $21.4 \%$ & .379 \\
\hline 10. Desire for further physical examinations & $56.7 \%$ & $10.7 \%$ & $.000^{* * * *}$ \\
\hline 11. Frequency of medical consultations & & & $.000^{* * * *}$ \\
\hline none & $0 \%$ & $71.4 \%$ & \\
\hline 1 - 2 times & $20 \%$ & $25 \%$ & \\
\hline 3 - 6 times & $40 \%$ & $3.6 \%$ & \\
\hline$>6$ times & $40 \%$ & $0 \%$ & \\
\hline Test subjects with consultation $\geq 1$ & $\mathrm{~N}=30$ & $\mathrm{~N}=8$ & \\
\hline 12. No precise cause of the complaints found ${ }^{\mathrm{b}}$ & $\mathrm{N}=25$ & $\mathrm{~N}=2$ & \\
\hline $\begin{array}{l}\text { 13. Diminished perception of one’s own } \\
\text { physical health }^{\mathrm{b}}\end{array}$ & $\mathrm{N}=16$ & $\mathrm{~N}=1$ & \\
\hline 14. Desire for further clarification of causes ${ }^{b}$ & $\mathrm{~N}=17$ & $\mathrm{~N}=2$ & \\
\hline 15. Need of aid from a third party & $26.7 \%$ & $3.6 \%$ & $.026^{*}$ \\
\hline 16. Lack of being taken seriously & $36.7 \%$ & $7.1 \%$ & $.011^{*}$ \\
\hline 17. Intake of medication & $76.7 \%$ & $17.9 \%$ & $.000^{* * *}$ \\
\hline 18. Duration of complaints & & & $.000^{* * * *}$ \\
\hline$<1$ month & $0 \%$ & $48 \%$ & \\
\hline 1 to 6 months & $23.3 \%$ & $28 \%$ & \\
\hline$>6$ months & $40 \%$ & $24 \%$ & \\
\hline$>2$ years & $36.7 \%$ & $0 \%$ & \\
\hline \multicolumn{4}{|l|}{ Questions on differential diagnoses } \\
\hline 19. DD Panic attacks & $27.6 \%$ & $10.0 \%$ & .104 \\
\hline 20. DD Hypochondria & $25.0 \%$ & $0.0 \%$ & $.004^{*}$ \\
\hline 21. DD Dysmorphophobia & $3.4 \%$ & $6.7 \%$ & 1.0 \\
\hline
\end{tabular}

Chi2-Test: ${ }^{*} p<.05,{ }^{* *} p<.01,{ }^{* * *} p<.001 . \mathrm{b}=$ only answered by test subjects with $\geq 1$ consultation.

of "clinical diagnosis" according to ICD-10 and "no clinical diagnosis". Finally, in order to highlight the superiority of the SOMS-CA over the GSCL-C in terms of differentiation, the ROC-curves of the two questionnaires have been compared using the statistical software package MedCalc.

The study has been approved by the appropriate ethics committee and has therefore been performed in accordance with the ethical standards laid down in the 1964 Declaration of Helsinki.

\section{Results}

\subsection{Comparison between the Patients and the Healthy Control Group}

The total score of complaints in the patient group is significantly higher than in the control group $(\mathrm{T}=4.2 \mathrm{df}=$ 43.9, $\left.p=.000^{* * *}\right)$. The average for the sum of all physical complaints for the patients was $9.2(\mathrm{~S}=6.2)$ and for the control group $3.8(\mathrm{~S}=3.3)$. Upon observation of the 31 individual physical symptoms, it was found that the frequency of 12 symptoms in particular varied significantly between the patient and control groups (Table 2). From a total of 17 questions on quality of life and illness-specific behaviour, significant differences between the patients and control group were observed in twelve questions (Table 3). 


\subsection{ROC Curve: Sensitivity, Specificity and Cut Off}

The area under the ROC curve is AUC (area under the curve) $=.983(\mathrm{SE}=0.14 ; \mathrm{n}=61)$. The differentiation ability of the SOMS-CA according to the heuristics of Janssen and Laatz (2010) is outstanding since the AUC is $>$.9. The SOMS-CA can therefore differentiate accurately between patients with somatoform disorders and healthy test patients. The curve path can be seen in Figure 1. An optimal cut off value of 3.5 was generated, resulting in a point score of $\geq 4$ which is categorised as conspicuous in the evaluation (Table 4). The sensitivity reached $97.6 \%$ which means that all but one of the patients were classified as conspicuous by the SOMS-CA. The resultant specificity was also very high at $96.8 \%$ which means that $96.8 \%$ of the healthy test subjects were categorised as inconspicuous such that the probability of being falsely categorised by the SOMS-CA as conspicuous without a clinical diagnosis is very low at $3.2 \%$.

A comparison of the AUC of the SOMS-CA total score (symptom list plus additional questions on quality of life and illness behaviour) and the GSCL-C shows that the SOMS-CA is superior in terms of differentiation between the patient and the control group. The AUC result of the SOMS-CA total score is much higher compared to the GSCL-C. According to Janssen and Laatz (2010) the low AUC of the GSCL-C (result < .7) is unacceptable. A comparison of the ROC-curves for the SOMS-CA total score, the SOMS-CA sympom list (without additional questions) and the GSCL-C shows that the SOMS-CA total score delivers the most convincing results and differentiates the best between the two groups (Figure 1 and Table 5).

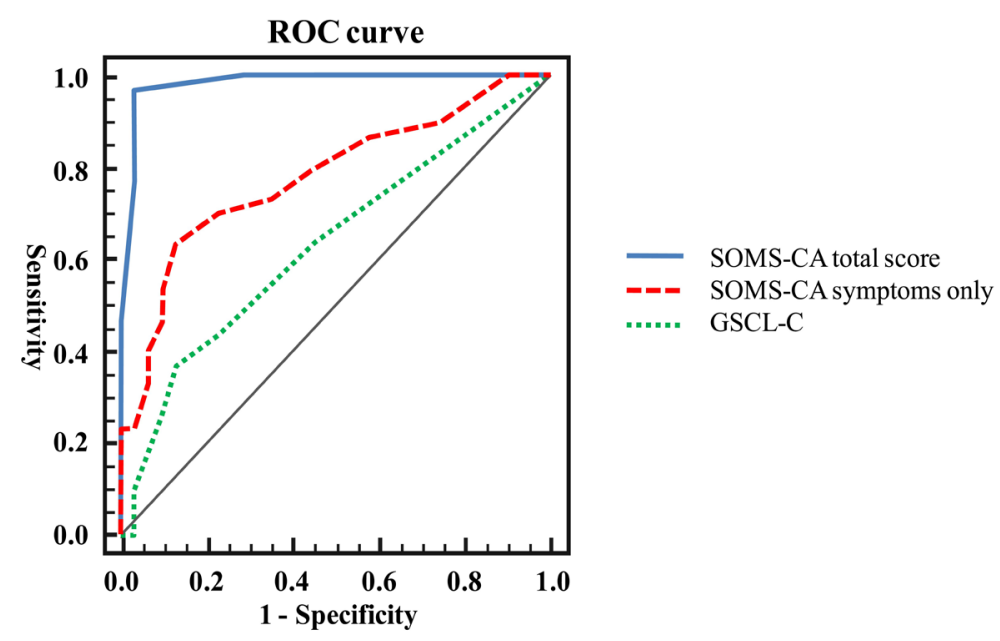

Figure 1. ROC-curves of the SOMS-CA (total score and symptom list only) and the GSCL-C.

Table 4. Potential cut-off values for the SOMS-CA study sample $(\mathrm{N}=61)$ of patients $(\mathrm{N}=30)$ and control group $(\mathrm{N}=31)$; Sensitivities, Specificities and the Youden index.

\begin{tabular}{cccc}
\hline Cut-off values $^{*}$ & Sensitivity & Specificity & \multicolumn{2}{c}{ Youden index } \\
\hline-1.00 & 1.000 & .000 & .000 \\
.50 & 1.000 & .097 & .097 \\
1.50 & 1.000 & .258 & .258 \\
2.50 & 1.000 & .71 & .710 \\
3.50 & .967 & .968 & .935 \\
4.50 & .900 & .968 & .868 \\
5.50 & .767 & .968 & .735 \\
6.50 & .467 & 1.000 & .467 \\
8.00 & .000 & 1.000 & .000
\end{tabular}

*Result is positive when total score of the SOMS-CA is greater or equal to the cut-off value. 
Table 5. AUC (Areas under the curve) of the ROC-curves of the SOMS-CA and the GSCL-C.

\begin{tabular}{cccc}
\hline Questionnaire & AUC & SE & $95 \%$ CI \\
\hline SOMS-CA total & .983 & .0135 & .912 to 1.000 \\
SOMS-CA symptoms only & .781 & .0602 & .656 to .876 \\
GSCL-C & .629 & .0685 & .496 to .749 \\
\hline
\end{tabular}

\section{Discussion}

The present study showed that the SOMS-CA can differentiate effectively between children and adolescents with clinically diagnosed somatoform disorders and children and adolescents from a healthy control group. When comparing the clinical sample with a healthy control group using a ROC curve, the SOMS-CA provided an excellent classification performance. With a cut off value of 3.5, the sensitivity (97.6\%) and specificity (96.8\%) were both very good.

The ROC curve demonstrates the strong differentiability of the SOMS-CA. Application of the SOMS-CA on a clinical population with somatoform disorders resulted in only one patient being classified as false negative. This patient had a dissociative disorder. This may signify that the SOMS-CA can better identify patients with somatoform disorders than those with dissociative disorders. This could be related to the higher frequency of shorter symptom durations and resulting lower scores.

On the other hand, only one healthy test subject was identified as conspicuous by the SOMS-CA. In the extensive companion diagnostics however, this subject did not fully satisfy the criteria for a mental illness. Subclinical mental problems however cannot be excluded for the subject. Subsequently, the SOMS-CA might also identify mental problems, which are insufficient for a psychiatric diagnosis. Moreover, up until two years previously, the subject suffered regularly from migraines which became sporadic and less common by the time of investigation. Therefore it must be taken into account that the SOMS-CA identifies conspicuous findings even in subjects with prolonged physical illnesses. Investigations using the SOMS-CA are currently being carried out on children with chronic somatic illnesses.

As can be seen from the results shown, the SOMS-CA has been verified by clinical practical experience.

A comparison between the AUC of the ROC-curve from the two questionnaires SOMS-CA and GSCL-C showed that the SOMS-CA is a superior instrument to assess children and adolescents with somatoform disorders and to detect healthy subjects as inconspicuous because of its symptom list and in inclusion of additional questions on quality of life and illness behaviour. These results highlight the fact that questions on illness specific behaviour and changes in quality of life are decisive factors on the assessment of somatoform disorders.

Additionally it is to be noted that diminished perception of personal health and denial of medical findings in children and adolescents with somatoform disorders is influenced by the caregiver (Noeker, 2008). For this reason a SOMS-CA "parent questionnaire" has been developed which shows satisfactory results for its sensitivity and specificity (Voss, 2012).

The health economic implications due to the demands on the paediatric primary care for both physical complaints and simultaneous psychosocial strain are extremely high: (Bernal et al., 2000; Briggs-Gowan, Horwitz, Schwab-Stone, Leventhal, \& Leaf, 2000; Noeker, 2008). The public health sector is put under strain on the one hand by frequent doctors' visits and subsequent diagnostic investigations (Reid, Wessely, Crayford, \& Hotopf, 2002), on the other hand by the impending chronification of the clinical picture as a result of deficient child and youth psychiatric diagnostics and treatment (Benjamin \& Eminson, 1992).

A limitation of the present study which must be acknowledged is the small sample which means that the results may not be regarded as representative of the general population. The number of study subjects is small because of the elaborate study design and its detailed examination process. It must also be acknowledged that this study deals with a severe clinical sample for which a selection process of participants had already taken place. As a further point of criticism, the clinical diagnosis used as the current gold standard can be adduced. Since there is currently no diagnostic manual for the assessment of somatoform disorders, the diagnosis of patients would be determined in a clinical interview by experts with clinical experience and used as the gold standard.

So far the SOMS-CA has not yet been tested on patients with other psychiatric diagnoses such as anxiety disorders and depressions. At present a study is being carried out on this topic in our workgroup. The SOMS-CA as a screening in an in- and out-patient population of our Department of Child and Adolescent Psychiatry, Psycho- 
somatics and Psychotherapy showed satisfactory results for its sensitivity and specificity (Voss, 2012).

Both psychiatric and physical illnesses may influence the results of the SOMS-CA. While all patients were seen by a paediatrician and were examined for organ pathological findings in response to their complaints, this did not take place for the selection of the healthy test subjects. The possibility therefore cannot be ruled out that healthy test subjects might have had undetected chronic or acute physical illness with organic findings, which might have influenced the results of the SOMS-CA.

\section{Conclusion}

The SOMS-CA successfully identifies patients with somatoform disorders from a paediatric population and differentiates from healthy test subjects. A comparison to the GSCL-C shows a considerable superiority of the SOMS-CA. Further studies on the validity of the SOMS-CA are in process, in particular the SOMS-CA as a screening for patients with other psychiatric disorders and for patients with chronic somatic diseases. Beyond this, data on a representative norm sample are to be collected. Age- and gender-specific as well as culturally specific norms should be considered. Results on reliability and on factor analysis are expected soon.

\section{References}

Achenbach, T. M. (1991a). Manual for the Child Behavior Checklist/4-18 and 1991 Profile. Burlington: University of Vermont, Department of Psychiatry.

Achenbach, T. M. (1991b). Manual for the Youth Self-Report and 1991 Profile. Burlington: University of Vermont, Department of Psychiatry.

Bass, C., \& Murphy, M. (1995). Somatoform and Personality Disorders: Syndromal Comorbidity and Overlapping Developmental Pathways. Journal of Psychosomatic Research, 39, 403-427. http://dx.doi.org/10.1016/0022-3999(94)00157-Z

Benjamin, S., \& Eminson, D. M. (1992). Abnormal Illness Behavior: Childhood Experiences and Long-Term Consequences. International Review of Psychiatry, 4, 55-69. http://dx.doi.org/10.3109/09540269209066302

Bernal, P., Estroff, D. B., Aboudarham, J. F., Murphy, M., Keller, A., \& Jellinek, M. S. (2000). Psychosocial Morbidity: The Economic Burden in a Pediatric Health Maintenance Organization Sample. Archives of Pediatrics \& Adolescent Medicine, 154, 261-266. http://dx.doi.org/10.1001/archpedi.154.3.261

Braehler, E. (1992). Der Gießener Beschwerdebogen für Kinder und Jugendliche GBB-KJ_Handanweisung. Bern: Hans Huber.

Briggs-Gowan, M. J., Horwitz, S. M., Schwab-Stone, M. E., Leventhal, J. M., \& Leaf, P. J. (2000). Mental Health in Pediatric Settings: Distribution of Disorders and Factors Related to Service Use. Journal of the American Academy of Child and Adolescent Psychiatry, 39, 841-849. http://dx.doi.org/10.1097/00004583-200007000-00012

Brockhaus, S. (2008). Symptome von somatoformen Störungen bei Kindern und Jugendlichen im Alter von 7-18 Jahren und Vergleich mit den Symptomen dieser Störungen bei Erwachsenen anhand von ICD-10 und DSM-IV. Berlin: Klinik für Psychiatrie, Psychosomatik und Psychotherapie des Kindes- und Jugendalters, Campus Virchow-Klinikum, CharitéUniversitätsmedizin Berlin.

Campo, J. V., Jansen-McWilliams, L., Comer, D. M., \& Kelleher, K. J. (1999). Somatization in Pediatric Primary Care: Association with Psychopathology, Functional Impairment, and Use of Services. Journal of the American Academy of Child and Adolescent Psychiatry, 38, 1093-1101. http://dx.doi.org/10.1097/00004583-199909000-00012

Di Lorenzo, C., Colletti, R. B., Lehmann, H. P., Boyle, J. T., Gerson, W. T., Hyams, J. S., Walker, L. et al. (2005). Chronic Abdominal Pain in Children. Pediatrics, 115, 812-815. http://dx.doi.org/10.1542/peds.2004-2497

Döpfner, M., \& Lehmkuhl, G. (2003). Diagnostik-System für psychische Störungen im Kindes- und Jugendalter nach ICD10 und DSM-IV (DISYPS-KJ) (2nd ed.). Bern: Hans Huber.

Eminson, M., Benjamin, S., Shortall, A., Woods, T., \& Faragher, B. (1996). Physical Symptoms and Illness Attitudes in Adolescents: An Epidemiological Study. Journal of Child Psychology and Psychiatry and Allied Disciplines, 37, 519-528. http://dx.doi.org/10.1111/j.1469-7610.1996.tb01438.x

Essau, C. A., Conradt, J., \& Petermann, F. (2000). Häufigkeit und Komorbidität Somatoformer Störungen bei Jugendlichen: Ergebnisse der Bremer Jugendstudie. Zeitschrift für Klinische Psychologie und Psychotherapie, 29, 97-108. http://dx.doi.org/10.1026//0084-5345.29.2.97

Fritz, G. K., Fritsch, S., \& Hagino, O. (1997). Somatoform Disorders in Children and Adolescents: A Review of the Past 10 Years. Journal of the American Academy of Child and Adolescent Psychiatry, 36, 1329-1338.

http://dx.doi.org/10.1097/00004583-199710000-00014 
Hotopf, M., Carr, S., Mayou, R., Wadsworth, M., \& Wessely, S. (1998). Why Do Children Have Chronic Abdominal Pain and What Happens to Them When They Grow Up? Population Based Cohort Study. BMJ, 316, 1196-1200. http://dx.doi.org/10.1136/bmj.316.7139.1196

Huertas-Ceballos, A. A., Logan, S., Bennett, C., \& Macarthur, C. (2009). Dietary Interventions for Recurrent Abdominal Pain (RAP) and Irritable Bowel Syndrome (IBS) in Childhood. Cochrane Database of Systematic Reviews, 1, CD003019. http://dx.doi.org/10.1002/14651858.CD003019.pub3

Janssen, J., \& Laatz, W. (2010). Statistische Datenanalyse mit SPSS für Windows. Eine anwendungsorientierte Einführung in das Basissystem und das Modul für Exakte Tests (6th ed.). Berlin: Springer. http://dx.doi.org/10.1007/978-3-642-01841-1

Kaufman, J., Birmaher, B., Brent, D., Rao, U., \& Ryan, N. (1996). Diagnostic Interview: Kiddie-Sads-Present and Lifetime Version (K-Sads-PL). Pittsburgh: University of Pittsburgh School of Medicine: Department of Psychiatry.

Lindley, K. J., Glaser, D., \& Milla, P. J. (2005). Consumerism in Healthcare Can Be Detrimental to Child Health: Lessons from Children with Functional Abdominal Pain. Archives of Disease in Childhood, 90, 335-337. http://dx.doi.org/10.1136/adc.2003.032524

Noeker, M. (2008). Funktionelle und somatoforme Störungen im Kindes- und Jugendalter (Vol. 11). Göttingen: Hogrefe.

Perquin, C. W., Hunfeld, J. A., Hazebroek-Kampschreur, A. A., van Suijlekom-Smit, L. W., Passchier, J., Koes, B. W., \& van der Wouden, J. C. (2001). Insights in the Use of Health Care Services in Chronic Benign Pain in Childhood and Adolescence. Pain, 94, 205-213. http://dx.doi.org/10.1016/S0304-3959(01)00355-4

Pfeiffer, E., Schröder, G., \& Lehmkuhl, U. (1997). Somatoforme Störungen bei Kindern und Jugendlichen. Psychotherapie, 2, 102-105.

Reid, S., Wessely, S., Crayford, T., \& Hotopf, M. (2002). Frequent Attenders with Medically Unexplained Symptoms: Service Use and Costs in Secondary Care. The British Journal of Psychiatry: The Journal of Mental Science, 180, 248-253. http://dx.doi.org/10.1192/bjp.180.3.248

Rief, W., \& Hiller, W. (1999). Toward Empirically Based Criteria for the Classification of Somatoform Disorders. Journal of Psychosomatic Research, 46, 507-518. http://dx.doi.org/10.1016/S0022-3999(99)00023-9

Rief, W., \& Hiller, W. (2008). Screening für Somatoforme Störungen (SOMS). Manual. (2., vollständig überarbeitete und neu normierte Auflage). Bern: Hans Huber.

Tomasson, K., Kent, D., \& Coryell, W. (1991). Somatization and Conversion Disorders: Comorbidity and Demographics at Presentation. Acta Psychiatrica Scandinavica, 84, 288-293. http://dx.doi.org/10.1111/j.1600-0447.1991.tb03146.x

Voss, K. (2012). Vergleich des SOMS-KJ mit dem YSR und des SOMS-E mit der CBCL/4-18 hinsichtlich der Klassifikation somatoformer Störungen in einer kinder- und jugendpsychiatrischen Inanspruchnahmepopulation.

Walker, L. S., \& Garber, J. (1992). Children’s Somatization Inventory: Preliminary Manual. Nashville: Vanderbilt University Medical Center.

Walker, L. S., Garber, J., \& Greene, J. W. (1991). Somatization Symptoms in Pediatric Abdominal Pain Patients: Relation to Chronicity of Abdominal Pain and Parent Somatization. Journal of Abnormal Child Psychology, 19, 379-394. http://dx.doi.org/10.1007/BF00919084

Walker, L. S., Garber, J., Smith, C. A., Van Slyke, D. A., \& Claar, R. L. (2001). The Relation of Daily Stressors to Somatic and Emotional Symptoms in Children with and without Recurrent Abdominal Pain. Journal of Consulting and Clinical Psychology, 69, 85-91. http://dx.doi.org/10.1037/0022-006X.69.1.85

Wedekind, D., Bandelow, B., Fentzahn, E., Trumper, P., \& Ruther, E. (2007). The Quantification Inventory for Somatoform Syndromes (QUISS): A Novel Instrument for the Assessment of Severity. European Archives of Psychiatry and Clinical Neuroscience, 257, 153-163. http://dx.doi.org/10.1007/s00406-006-0700-4

Weiß, R. H. (2006). CFT 20-R Grundintelligenztest Skala 2-Revision. Göttingen: Hogrefe.

Winter, S., Koeberle, C., Lenz, K., Pfeiffer, E., \& Lehmkuhl, U. (2012). Systematik Somatoformer Störungen. Monatsschrift Kinderheilkunde, 160, 20-26.

Winter, S., Koeberle, C., Lenz, K., Pfeiffer, E., \& Lehmkuhl, U. (2013). Systematik Somatoformer Störungen des Kindesund Jugendalters. Praxis der Kinderpsychologie und Kinderpsychiatrie, 9, 639-669.

Wittchen, H. U., \& Pfister, H. (1997). DIA-X-Interviews: Manual für Screening-Verfahren und Interview; Interviewheft Längsschnittuntersuchung (DIA-X-Lifetime); Ergänzungsheft (DIA-X-Lifetime); Interviewheft Querschnittuntersuchung (DIA-X-12 Monate); Ergänzungsheft (DIA-X-12Monate); PC-Programm zur Durchführung des Interviews (Längs- und Querschnittuntersuchung); Auswertungsprogramm. Frankfurt: Swets \& Zeitlinger. 
Scientific Research Publishing (SCIRP) is one of the largest Open Access journal publishers. It is currently publishing more than 200 open access, online, peer-reviewed journals covering a wide range of academic disciplines. SCIRP serves the worldwide academic communities and contributes to the progress and application of science with its publication.

Other selected journals from SCIRP are listed as below. Submit your manuscript to us via either submit@scirp.org or Online Submission Portal.
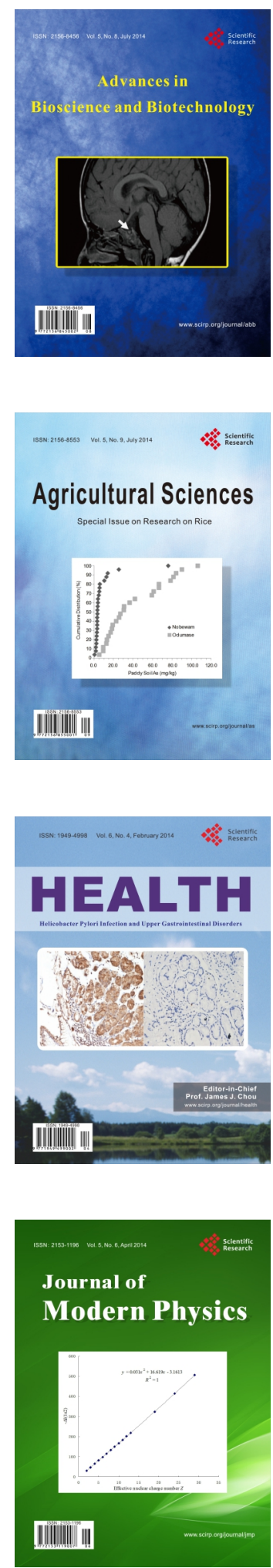
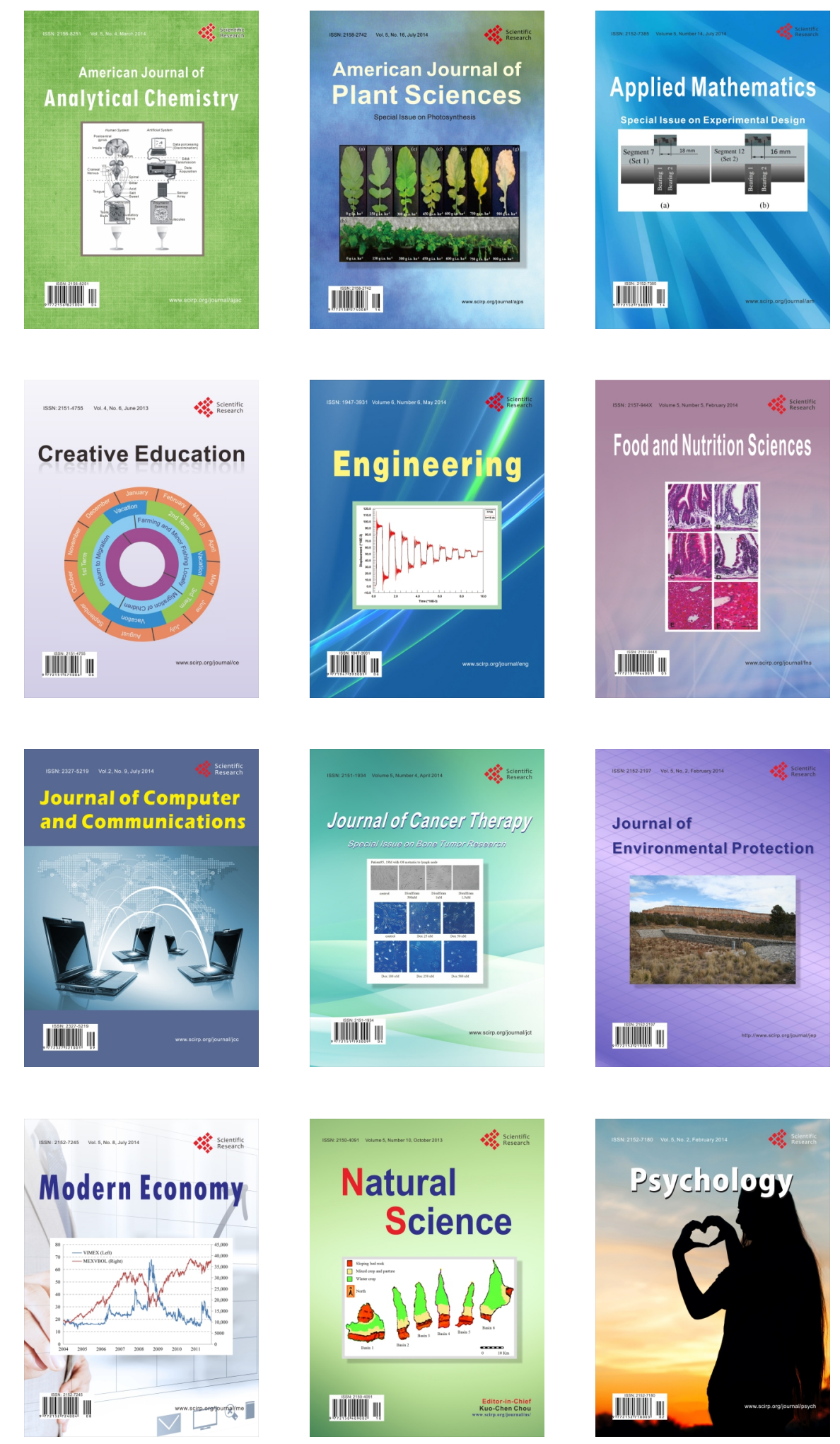